NÚMERO 5 | febrero - julio 2022 | 34-58

Revista de teoría literaria y literatura comparada

DOI: 10.22201/ffyl.nuevaspoligrafias.2022.5.1551

Recibido: 31-06-2021 | Aceptado: 28 -09-2021

\title{
Del espíritu de las narrativas Pasadas en Oliver TWIST
}

\author{
Of the Spirit of Narratives Past in Oliver Twist
}

\author{
Anaclara CASTro-SANTANA \\ Facultad de Filosofía y Letras \\ Universidad Nacional Autónoma de México | México \\ Contacto: anaclaracastro@filos.unam.mx
}

\begin{abstract}
Resumen
Oliver Twist, el huérfano más célebre de la literatura, hizo su aparición en las páginas de Bentley’s Miscellany en febrero de 1837. Desde entonces, su historia ha figurado en todo tipo de medios textuales y audiovisuales, de suerte que la imagen del infante de familia desconocida, cuya inocencia le lleva a triunfar ante la injusticia social que lo asedia, guarda una relación indisoluble con la obra de Charles Dickens. El linaje diegético del expósito Oliver se descubre en las páginas finales de la novela que lleva su nombre. Su genealogía artístico-literaria, sin embargo, es un secreto a voces que inspira personajes peculiares y una estructura narrativa basada en coincidencias y revelaciones. En este artículo se exploran algunas de las conexiones más relevantes entre Oliver Twist y las narrativas dieciochescas que le antecedieron. En específico, se atienden los legados de las novelas de Henry Fielding y las narrativas visuales de William Hogarth, los cuales fueron determinantes no sólo en la representación tragicómica de las clases bajas - como se ha llegado a sugerir- sino también en la concepción del protagonista, la caracterización de personajes secundarios y el diseño de la trama principal.
\end{abstract}

Palabras clave: Oliver Twist; Dickens y sus influencias; huérfanos literarios; Henry Fielding; William Hogarth; relaciones arte-texto

\begin{abstract}
Oliver Twist, literature's most famous orphan, made his first appearance in this world swaddled in the sheets of Bentley's Miscellany in February 1837. Since then, his history has been retold in all kinds of textual and audiovisual media. As a result, the image of the infant of unknown family origins, whose innocence leads him to triumph before ever lurking social injustice, is closely linked to that of Charles Dickens. Oliver's diegetic parentage is discovered in the final pages of the book. His literary and artistic ancestry, however, works as a whispered truth throughout the story, and it becomes instrumental in the shaping of peculiar characters and a narrative scaffolding built upon coincidences and revelations. This article explores some of the most relevant connections between Oliver Twist and preceding fictions from the eighteenth century. Specifically, it investigates the legacies of Henry Fielding and William Hogarth's novelistic and graphic productions upon Dickens's second novel, which determined not only the tragicomic representation of the lower classes-as scholarship has suggested-but also the very conception of the protagonist, the portrayal of secondary characters, and the laying out of the main plot.
\end{abstract}

Keywords: Oliver Twist; Dickens's influences; literary orphans; Henry Fielding; William Hogarth; text-art relations 
$\mathrm{L}$ a escena en la que Oliver Twist se levanta y, con toda timidez, pide una segunda porción del raquítico engrudo de avena con que alimentan a los infantes en la lúgubre casa parroquial forma parte del imaginario colectivo occidental. Como observa Ruth Richardson (2012: 1), la historia de Oliver, al igual que la de la criatura de Frankenstein, es de ésas que todo mundo conoce, a grandes rasgos, incluso si nunca ha leído el libro. Y es que, a lo largo de sus casi dos siglos de existencia, la segunda novela de Charles Dickens ha sido reimpresa, reeditada, abreviada y reinventada en todo tipo de formatos impresos y audiovisuales. De acuerdo con Joss Marsh (2006), "sólo Dracula y Dr. Jekyll and Mr. Hyde superan Oliver Twist y A Christmas Carol [...] en la categoría de las narrativas más filmadas de todos los tiempos" (204). ${ }^{1} \mathrm{El}$ musical Oliver! (1960), de Lionel Bart, llevado al cine en 1968, ha mantenido su popularidad con reestrenos y nuevas producciones a lo largo de seis décadas (Davis, 2007: 289). Existen videojuegos (Playzido, s. f.), juegos de mesa (Boardgame Geek, s. f.), estampillas conmemorativas (Philatelic, 2012) y, en tiempos de pandemia Covid 19, hasta cubrebocas tematizados (Charles Dickens Museum, s. f.). No se trata de un fenómeno nuevo. Oliver Twist (1838) comenzó a ser adaptada, para el teatro, incluso antes de terminar de publicarse por entregas (Davis, 2007: 289). Desde el principio, la imagen del pequeño huérfano se ha construido en el ojo de la mente no sólo con palabras, sino también por medio de la ilustración, comenzando con las veinticuatro imágenes de George Cruikshank que acompañaron la publicación serial en Bentley's Miscellany y las primeras ediciones en formato de libro. Desde entonces, el delicado Oliver, con sus modales tan impecables como inverosímiles, es un ícono de la inocencia inmaculada como víctima favorita de la injusticia social.

Muchos de quienes hoy recuerdan a Oliver saben poco o nada de Tom, otro huérfano literario celebérrimo en su momento, quien hiciera su aparición un centenar de años antes que el de Dickens, en las páginas de la obra más conocida de Henry Fielding, The History of Tom Jones, a Foundling (1749). En la actualidad, el nombre “Tom Jones" evoca con mucha mayor inmediatez al galés intérprete de la pieza musical "It's Not Unusual" que al protagonista de aquella vasta novela de formación dieciochesca. ${ }^{2}$ Mas cuando las y los lectores originales escuchaban en su cabeza a la

1 "Only Dracula and Dr. Jekyll and Mr. Hyde beat out Oliver Twist and A Christmas Carol [...] for the status of most-filmed single fiction in history". La traducción de esta cita y de todas las referencias críticas subsecuentes son mías. Las fuentes primarias se citarán en el idioma original.

2 El cantante Tom Jones tomó su nombre artístico de aquella obra. En una curiosa ironía, ese gesto (quizá reverencial, quizá sólo práctico) ha contribuido a la distorsión del personaje de Fielding y quizá a la margi- 
voz narrativa de Oliver Twist contar cómo "in this workhouse was born [...] the item of mortality whose name is prefixed to the head of this chapter" (Dickens, 1993: 17), Fielding y sus novelas figuraban de manera prominente. A decir de algunos, Fielding era responsable de haber creado una nueva especie de escritura (a new species of writing). Esto es, una biografía ficticia pero verosímil, permeada por el humor y estructurada en episodios autónomos entrelazados entre sí (An Essay of the New, 1751: 16-18). Autores del cambio de siglo, como Anna Laetitita Barbauld, se declaraban fervientes admiradores de la comicidad y variedad de los personajes creados por Fielding (citada en Michie, 1999: 93). Samuel Taylor Coleridge (1835: 339) consideraba a Tom Jones una de las tres tramas más perfectas de la literatura. Para Sir Walter Scott, Fielding era, nada más y nada menos, que el "padre de la novela inglesa" (citado en Keymer, 2005: XVI), un calificativo que, desde luego, hoy se toma con más de una pizca de sal. En la primera mitad del siglo xIx, Tom y sus aventuras eran grandes favoritos entre el público lector no especializado, como lo sugieren los numerosos folletines y versiones abreviadas de la novela que circulaban entonces (Fergus, 2006: $167 \mathrm{y}$ 176). Como se verá en este artículo, más allá de revelar que Edwin Leeward y Agnes Fleming son los progenitores difuntos de Oliver, las páginas de Dickens sugieren que su huérfano es de la misma estirpe que el expósito Tom, pues la novela de Fielding es uno de los hipotextos fundamentales de Oliver Twist, or the Parish Boy's Progress.

El título completo del texto de Dickens sugiere otra conexión indisoluble con el siglo xviII, pues constituye una alusión a las entonces famosísimas narrativas visuales de William Hogarth, en concreto, A Harlot's Progress (1732) y A Rake's Progress (1734), sus dos primeras series satíricas de sujetos modernos. De forma menos obvia, pero de igual manera poderosa, la temática de Oliver Twist, sus personajes y la cualidad gráfica del relato, en combinación con las ilustraciones que lo acompañaban, evocan el mundo visto a través de las manos de Hogarth en otras piezas menos conocidas ahora, pero que, gracias a su reproducción semimasiva, resultaban muy familiares en el siglo xix: Industry and Idleness (1747), The Four Stages of Cruelty (1751) y Gin Lane (1751). ${ }^{3}$ No por nada, una reseña anónima de Pickwick Papers

nalidad actual de la novela, puesto que, al destacar un aspecto de masculinidad conquistadora que no ocurre en la obra original, Tom Jones tiende a asociarse con la figura del mujeriego, lo cual suele ahuyentar a lectoras y lectores modernos. Se volverá a este punto más adelante en el artículo.

3 La obra pictórica de William Hogarth se encuentra resguardada en el museo Tate en Londres. Los grabados que aquí se mencionan pueden verse en su microsition dedicado al artista: https://www.tate.org.uk/art/ artists/william-hogarth-265. Para un cronología completa véase Hallett (2001: 337-339). 
publicada en 1836 identificaba a Dickens como "el Hogarth literario del momento" (Bell's Life, 1836: 2). ${ }^{4}$ Tanto el bajo mundo del crimen y la pobreza abyecta que aparecen en Oliver Twist, como la dicotomía entre personajes que se dejan llevar por sus circunstancias y aquellos que, al resistirlas, triunfan como ejemplos morales, tienen sus semillas de representación en el arte de Hogarth.

En las páginas siguientes se exploran con detenimiento los ecos dieciochescos de Fielding y Hogarth en Oliver Twist que tienden a olvidarse en la actualidad, pero que resultaban mucho más inmediatos $-\mathrm{y}$ relevantes- para sus lectoras y lectores originales. El artículo busca demostrar la importancia de estas relaciones intertextuales para una comprensión más profunda y disfrutable de la novela de Dickens. Al mismo tiempo, se postula que Oliver Twist constituye una suerte de homenaje al siglo anterior que, como sucede con frecuencia en los buenos tributos, termina por reemplazar y llevar al olvido a las fuentes de inspiración primigenias. Rastrear la tradición dieciochesca detrás de la novela temprana más famosa de Dickens da cuenta de cómo, al escribir con el dedo en la llaga del presente, el joven autor miraba al pasado en busca de inspiración y aliento.

Reconocer la influencia de novelistas dieciochescos en Dickens no es, en modo alguno, una revelación inusitada. Con cierta frecuencia, la crítica enumera a Fielding y otros autores (por ejemplo, Tobias Smollett, Daniel Defoe y Oliver Goldsmith) entre las inspiraciones del escritor decimonónico. Sin embargo, estas menciones por lo general son formulistas y apresuradas. Se habla, por ejemplo, de la manera en que Oliver Twist "refleja la pasión infantil [del autor] por las novelas picarescas del siglo xviII, Tom Jones y Roderick Random", y la forma en que "la trama de Oliver Twist, al igual que la de las novelas de Fielding y Smollett, gira en torno a la ilegitimidad y una herencia en disputa" (Muller, 2003: 41). ${ }^{5}$ Del mismo modo, piezas críticas dedicadas a indagar influencias literarias notan cómo "las tramas melodramáticas y los personajes grotescos de Dickens tienen una deuda literaria con la tradición picaresca del siglo xviII" (McCuskey, 2001: 128). ${ }^{6}$ No obstante, rara vez se examinan las semejanzas precisas o sus alcances. Algo similar sucede con la influencia de Hogarth. Aunque en

4 "the literary Hogarth of the day".

5 "Dickens's second novel reflects his childhood passion for the eighteenth-century picaresque novels Tom Jones and Roderick Random. As in the novels by Henry Fielding and Tobias Smollett, the plot of Oliver Twist revolves around illegitimacy and disputed inheritance".

6 "the melodramatic plots and grotesque characters of Dickens's fiction owe at least as much [...] to the eighteenth-century picaresque tradition". 
ocasiones se menciona la alusión que hace Dickens a los "progresos" satíricos del libertino y la prostituta por medio del título completo de Oliver Twist, no se abunda en las maneras en que las imágenes evocadas en la novela, y la trama misma, siguen muy de cerca las narrativas pictóricas del artista dieciochesco. Tampoco se exploran las implicaciones de estos vínculos en cuanto a la cualidad casi táctil de las descripciones dickensianas. Como mostraré en este artículo, sin embargo, los legados dieciochescos -en especial los de Fielding y Hogarth- en Oliver Twist son mucho más profundos de lo que normalmente se reconoce.

Para empezar, los parecidos con Tom Jones van más allá de su supuesto carácter "picaresco", término cuya pertinencia para describir aquella novela es por demás inapropiada, como apunta la crítica más especializada en ese tema. En palabras de Harry Sieber (2018), por ejemplo, "designar a Tom Jones como novela picaresca es ignorar por completo que el modelo de Fielding es Don Quijote y no Guzmán y sus seguidores" (212). ${ }^{7}$ Como afirma J. A. Garrido Ardila (2015), el prestigio del adjetivo "picaresco" cuando se asocia a narrativas posteriores al siglo XvII es tal que sus fronteras se han vuelto cada vez más difusas y "el término con frecuencia se emplea de manera descuidada para describir novelas que, en un sentido estricto, son, de manera evidente, no picarescas, como Don Quijote y Tom Jones" (1). ${ }^{8}$ Si bien Tom Jones y, en menor medida, Oliver Twist tienen un carácter episódico, y la novela de Dickens (no así la de Fielding) se enfoca en la representación satírica de los bajos mundos - características asociadas con la picaresca (Ardila, 2015: 14-15) - la perspectiva narrativa de ambas novelas, con su tendencia a la omnisciencia diegética y a la superioridad intelectual, en el caso de Fielding, y moral, en el de Dickens, está por completo alejada de las voces confianzudas y socarronas que narran el Lazarillo de Tormes (1550-2?) y el Guzmán de Alfarache (1599, 1604), los grandes prototipos del género picaresco. En estos últimos, los protagonistas relatan sus vidas de manera directa, intercalando frecuentes guiños a sus lectoras y lectores implícitos, para justificar sus procederes más cuestionables y crear un ambiente de cierta complicidad. En Tom Jones, en cambio, la voz narrativa funciona a manera de filtro entre las acciones de los personajes y las reflexiones que éstas deben provocar en quienes las leen. Un

7 "to call Tom Jones a picaresque novel is to ignore completely the fact that Don Quixote, not Guzmán and his followers, was Fielding's model”.

8 "so thin have some critics spread the term that it has been often been loosely applied to novels that are, in the strictest sense, conspicuously non-picaresque, such as Don Quixote and Tom Jones". 
efecto similar se busca en la novela de Dickens, como se abordará con mayor amplitud en páginas subsecuentes.

Por otra parte, las conexiones de Oliver Twist con la obra narrativa de Fielding exceden las fronteras de Tom Jones. La representación del mundo criminal en el texto de Dickens ostenta paralelismos significativos con Jonathan Wild (1743), la tercera novela del autor dieciochesco, la cual versa sobre las aventuras de un cazarrecompensas dedicado a obtener dinero de bienes robados, para después delatar a quienes realizan el hurto. Asimismo, el patetismo de Oliver Twist - su tendencia a conmover por medio del despliegue de la injusticia desmedida - es reminiscente de Amelia (1751), la novela final de Fielding, en la que se muestran los lados más oscuros de la hipocresía en todos los niveles sociales. A mi modo de verlo, más que simplemente ostentar una "deuda literaria con la tradición picaresca del siglo xvıII", como sugiere McCusky en el pasaje reproducido más arriba, el texto de Dickens retoma temas y motivos estructurales de la obra de Fielding tales como la doble moral, el arribismo social y la insensibilidad derivada de la supervivencia cotidiana en un mundo permeado por una creciente ideología burguesa que proponía que el individualismo era el motor principal del progreso. En el plano personal, el histriónico Dickens comparte con Fielding (quien fuera dramaturgo antes que prosista) la pasión por la teatralidad. Esto se ve reflejado, por ejemplo, en el intrusismo característico de la voz narrativa de ambos autores, así como en la cualidad escénica de las descripciones y los diálogos en sus novelas.

Los ecos hogarthianos en Dickens también trascienden la idea del progreso irónico, en el que la aspiración al hedonismo burgués lleva al declive moral y, en última instancia, a la locura o a la muerte indigna. La brutalidad creciente de Sikes en Oliver Twist, por ejemplo, recuerda la crueldad progresiva de Tom Nero en The Four Stages of Cruelty de Hogarth. Las descripciones de los arrabales donde habitan los criminales que se apoderan de Oliver, además de representar las condiciones reales de los distritos londinenses más pobres en la época de Dickens, recuerdan las estremecedoras imágenes de Gin Street labradas por el artista dieciochesco. ${ }^{9}$ Del mismo modo, el episodio en que Oliver trabaja como aprendiz de enterrador evoca la oposición entre

9 Utilizo el término "labrar" en este caso puesto que Gin Lane, al igual que el resto de la obra gráfica de Hogarth a la que se hace referencia en este artículo, consistía en grabados (engravings) que se trabajaban primero en una placa metálica, para después imprimirse y venderse a bajo costo. Versiones de mejor calidad de estas mismas ilustraciones podían verse en cafés, tabernas y galerías especializadas en la venta y exhibición de estos materiales (Hallett, 2001: 15-16). 
el discípulo trabajador y el ocioso en Industry and Idleness de Hogarth. Pero vayamos por partes.

\section{Del expósito Tom al huérfano Oliver}

$\mathrm{Al}$ inicio de Tom Jones, a su regreso de un viaje de negocios, el terrateniente y magistrado Squire Allworthy descubre un bebé abandonado en su habitación. Tras realizar indagaciones erróneas y atribuirle una genealogía equivocada al infante (que lo identifica como hijo natural de un sanchesco maestro parroquial y una mucama), Allworthy acoge al niño y lo educa a la par de su sobrino, Blifil, bajo el entendido de que, no obstante vivir con las comodidades de un latifundista, su futuro no está en modo alguno asegurado. La trama de la novela sigue, de forma episódica, el desarrollo de Tom hasta su juventud, cuando su involucramiento en un triángulo amoroso con Blifil y una virtuosa - y acaudalada - vecina causa la expulsión injustificada del huérfano de la mansión provinciana. Después de muchas aventuras, caminos cruzados y equivocaciones, la trama llega a su desenlace en Londres, cuando, en el nadir de los infortunios de Tom, se descubre que en realidad es el sobrino mayor de Allworthy, cuya identidad había sido revelada por su madre en una carta entregada a Blifil justo antes de morir - misma que el mezquino medio hermano había ocultado con el fin de preservar su herencia intacta.

Como sugiere este breve resumen, los parecidos entre Tom y Oliver se centran, por una parte, en su calidad de huérfanos - condición que los margina y los vuelve vulnerables al engaño y la explotación-. En Oliver Twist, como se recordará, el niño - cuya madre expira al dar a luz- pasa de un orfanato parroquial a una casa de asistencia y de ahí a ser aprendiz de un enterrador, de quien escapa tras ser tratado con gran crueldad. Más adelante, casi muerto de hambre camino a Londres, es rescatado y después engatusado por un grupo de ladronzuelos. Tras muchas peripecias en las que es acogido por dos familias distintas, secuestrado por los ladrones y obligado a participar en un robo, se revela que es hijo de una pareja respetable que estaba a punto de contraer matrimonio y que su padre le había legado una fortuna antes de morir. Mientras sus circunstancias familiares se desconocen, la integridad física y la libertad de Oliver corren constante peligro. Si bien el trayecto de Tom es distinto, pues en su infancia goza de las comodidades que siempre le son negadas a Oliver, la ausencia de lazos familiares también lo pone en riesgo en diversos momentos, como 
cuando es reclutado en calidad de soldado raso para ir a la guerra que se libra al norte del país (libro viI, capítulos 11 y 12), o cuando es encarcelado por haber presuntamente matado a quien lo provocara en una riña (libro xvı, capítulo 10). Tom y Oliver son víctimas permanentes del doble estándar de clase y rango social, el cual es uno de los ejes centrales del mundo diegético de sus respectivas novelas. En tanto que no se sabe quiénes son sus progenitores, su vida es de dudoso valor para quienes se van encontrando en el camino. Asimismo, de forma irónica, las aventuras y desdichas de los personajes - en el caso de Fielding más tendientes a lo cómico y en el de Dickens a lo patético- son presentadas para el divertimento voyerista de sus lectores, si bien ambas obras ofrecen lecciones morales sobre la falta de humanidad de la naturaleza humana.

Por otra parte, con respecto a la trama que se urde en torno a la genealogía y postrera asignación de herencia de los protagonistas, ambas novelas comparten el uso de una revelación que se va anticipando y construyendo de manera paulatina, pero que no ocurre de lleno sino hasta el final de la historia. Al igual que hace Fielding con Tom, Dickens dota a Oliver de un medio hermano que actúa en su contra a lo largo de su existencia, motivado por la ambición económica. En Oliver Twist, el misterioso villano Monks se descubre como Edward Leeward, medio hermano consanguíneo del huérfano. En Tom Jones, como ya se dijo, Blifil, quien se muestra como antagonista de Tom a lo largo de la narrativa (pero sin explicar del todo la causa de su antipatía), se devela al final de ésta como medio hermano uterino del protagonista. En ambos textos, la motivación exacta de estas fuerzas adversas no es clara, ni para los habitantes de la diégesis ni para las y los lectores que se acercan por primera vez al texto. La obra de Dickens, al igual que la de Fielding, se construye a la manera de un rompecabezas en el que cada episodio revela una pieza más de información. Una vez leído, el desenlace activa un proceso mental de reconstrucción retrospectiva en el que todas las señales terminan por entenderse. Esta técnica —que Wolfgang Iser (1974: 29-56) identifica como el recurso maestro de Fieldinges replicada por Dickens no sólo en Oliver Twist sino también en novelas posteriores, entre las cuales destaca sin duda Great Expectations (1861). ${ }^{10}$

Además de estos paralelismos entre los protagonistas y la trama principal, a lo largo de Oliver Twist hay numerosas reminiscencias de Tom Jones. La adopción de

10 Pienso, en particular, en la famosa revelación, fatídica para Pip, sobre la identidad de su misterioso benefactor: el exconvicto Abel Magwitch, a quien el niño ayudara bajo amenazas al inicio de la novela. 
Tom al principio de la novela de Fielding, por ejemplo, se replica en gran medida en la subtrama de Rose Maylie, una chica huérfana, quien es acogida por Mrs. Maylie y vive en calidad de sobrina de ésta, pero es considerada impropia para ser esposa del hijo, dada su posible ilegitimidad. Personajes como el dignatario de la casa parroquial, quien ante las súplicas del huérfano de no ser enviado a una muerte segura siendo aprendiz del limpia chimeneas responde, "Well! of all the artful and designing orphans that ever I see, Oliver, you are one of the most bare-facedest" (Dickens, 1993: 35), están cortados con la misma tijera que Thwackum, el sádico tutor "whose meditations were full of birch and exclaimed against [...] wicked lenity", cuyo tema favorito era "the correction of children" y quien gustaba de azotar a Tom hasta que "he could flea his skin" (Fielding, 2005: 119-20, 125). Los títulos de los capítulos en la novela de Dickens evocan con fuerza los de la de Fielding. El 36 de Oliver Twist, titulado "A Very Short One, and May Appear of No Great Importance in Its Place, but It Should Be Read Notwithstanding", recuerda encabezados en Tom Jones del tipo de "A Short Chapter; but which Contains Sufficient Matter to Affect the Good-Natured Reader" (libro vI, cap. 11) y "Containing Little or Nothing” (libro III, cap. 1). Esto es más que una coincidencia, puesto que, como señala el autor dieciochesco del Essay on the New Species of Writing referido al inicio de este artículo, la división capitular excéntrica se consideraba una de las aportaciones de Fielding a la prosa narrativa ( $A n$ Essay on the New, 1751: 18).

Quizás uno de los puntos de contacto más estridentes entre Oliver Twist y la novela de Fielding es la peculiar voz narrativa que relata la historia. De acuerdo con Linda Hutcheon (1980), "en Tom Jones es casi como si la relación primordial que establecen los lectores fuera con el narrador-escritor que funge como guía, en vez de con los personajes" (27). ${ }^{11}$ Algo similar puede decirse de quien narra la vida de Oliver. Si bien no existen disertaciones teóricas al inicio de cada libro como ocurre en Tom Jones, es difícil pasar por alto la forma en que se describe el primer llanto del recién huérfano: "Oliver cried lustily. If he could have known that he was an orphan, left to the tender mercies of church-wardens and overseers, perhaps he could have cried the louder" (Dickens, 1993: 19). Observaciones de este estilo, las cuales pueblan las páginas de Oliver Twist de forma continua, son características en Tom Jones. Sirva a modo de ejemplo un pasaje en que un matrimonio atormentado por penurias econó-

11 "In Tom Jones, it is almost as if the reader's primary relationship were meant to be with the guiding narrator writer, rather than with the characters". 
micas derivadas de una mentira vengativa de la esposa es "ayudada" por la Fortuna, quien "at lenght took pity on this miserable Couple, and considerably lessened the wretched state of [the husband], by putting a final end to that of his wife, who soon after caught the small-pox, and died" (Fielding, 2005: 95). El humor irónico de ambos pasajes - suministrado por un narrador que todo lo sabe, todo lo juzga y calla lo que le conviene- es análogo en las dos obras. Lo que se ha observado en Fielding sobre la influencia de su experiencia teatral en la concepción de escenas dramáticas en las novelas y narradores que se asemejan a prólogos o coros teatrales (Lockwood, 2008: 26-28) puede extenderse tanto a la cualidad escénica como a la voz narrativa en Oliver Twist. Y es que, como es bien sabido, Dickens tenía una pasión por el teatro, la cual pudo al fin combinar con su talento prosista en las lecturas dramatizadas de sus obras que comenzó a dar en 1858 y no dejó sino hasta su muerte en 1870.

\section{De joven apasionado a niño apacible}

Existen diferencias decisivas entre Oliver y Tom. La más evidente de ellas es, sin duda, la edad en la que se les representa en sus respectivas novelas. Mientras que Oliver pasa de ser un bebé, en las primeras páginas, a un niño prepúber - condición que conserva el resto del relato-, Tom abandona la infancia en el primer tercio del libro y de ahí en adelante es un joven adulto. El cambio en el énfasis entre la juventud y la infancia ilustra la bien conocida idea de que durante la primera mitad del siglo xIx la niñez comenzó a ser percibida como una etapa crucial (y con características muy particulares) en el desarrollo de las personas (Zornado, 2001). Asimismo, hacer de Oliver un niño, y mantenerlo así durante toda la novela, permite a Dickens, entre otras cosas, omitir el elemento sexual —que, desde finales del siglo xviII, resultaba problemático para quienes consideraban la obra de Fielding "indecente" o "inmoral" (Paulson y Lockwood, 1969: 167-168, 173-174). En Tom Jones, muchas de las aventuras cómicas - aunque no todas - tienen un subtexto pasional en cuanto a que el arco del personaje se basa en su aprendizaje sobre el valor de la prudencia, el control de los impulsos y, sobre todo, el no dejarse usar por quienes aparentan tener buenas intenciones, pero buscan sólo el beneficio propio. Cabe señalar, sin embargo, que las proezas sexuales de Tom no son, de ninguna manera, el foco principal de la novela de Fielding, como suele creerse en ocasiones. Hoy en día, esta noción se deriva probablemente de la adaptación fílmica más exitosa de esta obra, la película de 1963 de 
Tony Richardson, nominada a diez premios Óscar (ganadora de cuatro), y de donde el cantante galés Sir Thomas John Woodward tomó su nombre artístico “Tom Jones" (Bonfante, 1970). ${ }^{12}$ De forma paradójica, la hipersexualización de Tom en adaptaciones audiovisuales (reforzada en el pseudónimo del músico) ensombrece el tratamiento irónico que da Fielding al motivo del Don Juan, puesto que, en la novela, Tom con frecuencia es tratado, de manera cómica, cual objeto sexual. Su disposición perpetua se da por sentada a causa de la inestabilidad de su estatus social, en cuanto hijo ilegítimo de paternidad desconocida, con educación de terrateniente, pero carente de fortuna y oficio. En la novela, Tom no es un conquistador, sino alguien que no puede, o no ha aprendido, a decir que no.

En cualquier caso, al hacer del huérfano Oliver un niño permanente, Dickens no requiere tender un modesto velo sobre la tensión sexual (como lo hace en David Copperfield [1849-1850], por ejemplo). ${ }^{13}$ De acuerdo con Robert Patten (2006), la producción temprana de Dickens "se caracteriza por una regresividad intensiva: sus trayectorias apuntan hacia la recuperación de una suerte de niñez idílica, libre de las tentaciones y complicaciones de la sexualidad adulta" (25). ${ }^{14}$ En efecto, como ya se ha planteado aquí, Oliver llega a representar un ícono de la inocencia pura, asediada por todas las fuerzas negativas de la sociedad. Un personaje así requiere mantenerse alejado de los dilemas y los embarazos (físicos y morales) derivados de la sexualidad. Al mismo tiempo, como plantea Robert Newsom (2006: 92-96), es fácil simplificar en exceso la noción de que Dickens importa la perspectiva romántica de la niñez como un momento idílico, puesto que - en su caracterización de niños disruptivos y de adultos adora-niños que son ineptos para protegerlos - se mezclan matices sobre la vulnerabilidad de la infancia para caer en la tentación y la desobediencia. Así pues, al construir un protagonista niño, Dickens abre la posibilidad de su caída o corrupción por la sociedad, tal como les sucede a the Artful Dodger y a Nancy en un momento

12 Dicho filme explotó al máximo el aspecto amatorio de la obra original, haciendo de Tom un ícono de masculinidad conquistadora, a la manera de la franquicia de James Bond, personaje que hiciera su aparición en el cine el año anterior, en la película $\operatorname{Dr}$ No (1962).

13 Cabe notar que David Copperfield, cuya publicación por entregas inició en el centenario de la novela de Fielding, es otra obra de Dickens con ecos fieldinguescos importantes. De hecho, el protagonista-narrador menciona a Tom Jones de manera directa como uno de los libros favoritos de su infancia.

14 "characterized by an acute regressivity: their trajectories all point toward some kind of recovered, idyllic childhood free of the temptations and complications of adult sexuality". 
hipotético anterior que no se muestra en el relato. Ésta es una de las expectativas no realizadas que mantienen la tensión en la novela.

\section{"Bad, depraved, vicious taste"}

Antes de proceder a la invocación del espíritu de Hogarth en Dickens, quiero cerrar esta sección sobre Fielding notando algunos de los vínculos que ostenta Oliver Twist con otras novelas del autor dieciochesco además de Tom Jones. De acuerdo con la joven reina Victoria, su primer ministro le decía que Oliver Twist estaba escrita con "un estilo de mal gusto, depravado y ruin. Lea, por ejemplo, Jonathan Wild o Amelia y compruebe si no son exactamente la misma cosa" (citada en Bloom, 2008: 195-196). ${ }^{15}$ Los títulos que el interlocutor de la reina menciona para ejemplificar el carácter indigno de la novela de Dickens son reveladores. Como se comenta al inicio de este artículo, la atmósfera y el ambiente en que se sitúa Oliver Twist son reminiscentes de la tercera novela de Fielding, Jonathan Wild, una historia basada en la vida real de un famoso criminal de la época. La ocupación y duplicidad de Fagin como tutor de carteristas (a quienes delata cuando ya no le son de utilidad) recuerdan las del cazarrecompensas Wild, dedicado a entrenar ladrones, vender sus hurtos y más tarde denunciarlos. El personaje de Sikes, quien vive con (y en apariencia es proxeneta de) Nancy, también es una versión endurecida (y hasta cierto punto en espejo) de Wild, quien es estafado por prostitutas y se casa con una mujer que le es infiel con sus subalternos. Más allá del tema general y el parecido entre personajes como Wild y Sikes/Fagin, el mayor punto de contacto entre Twist y Wild es que sus autores buscan despojar del aire de gloria que envolvía a las superestrellas criminales en las biografías y Newgate accounts que circulaban en el siglo xvinI, y que se habían consolidado en formatos más extensos y populares con las Newgate novels del xIx.

La relación de Oliver Twist con Amelia, la última novela de Fielding, es de igual manera importante. De acuerdo con John Bowen (2000), "nadie podría haber predicho Oliver Twist con base en Pickwick Papers" (2), en cuanto que la comedia socarrona de la primera tiene poco en común con la atmósfera sombría de la segunda. ${ }^{16}$ Algo similar sucede con la publicación de Amelia, un relato donde el movimiento es

15 "a bad, depraved, vicious taste; now just read Jonathan Wild ... and Amelia, and see if it isn't just the same thing".

16 "No one could have predicted Oliver Twist on the basis of Pickwick Papers". 
escaso, la comedia exigua y el sufrimiento constante, precedida por Tom Jones, una historia energética, dotada de un humor exuberante. Algunos personajes en Oliver Twist también son análogos a los de Amelia. Tal es el caso de Fang, el inepto y colérico magistrado que, sin escuchar siquiera el caso de Oliver, planea resolverlo "summarily" y sentenciar al niño "for three months-hard labour, of course" (Dickens, 1993: 79), quien es del mismo barro que Thrasher, un juez que "had never read one syllable of the law", pero encarcela a un acusado por ser "an Irishman, and that is always sufficient evidence with me", ordena un mes de trabajos forzados a una pobre mujer sólo por "having no money [...] declaring she was guilty of street-walking" y libera a quien lo soborna (Fielding, 2010: 64-65). Ambos magistrados ficticios trabajan en una cárcel real: la temida Newgate prison, donde la escena del esposo recluido da comienzo a Amelia y donde Fagin termina su participación en Oliver Twist, esperando ser ejecutado.

La lista de paralelismos entre las narrativas de Fielding y Oliver Twist podría continuar, pero es preciso parar aquí para poder dar cuenta de los ecos de Hogarth. Sólo queda terminar esta sección dedicada a la exploración de los rastros de Fielding mencionando un tributo desde el ángulo biográfico: el octavo hijo de Dickens, nacido en enero de 1849 - año del centenario de la publicación de Tom Jones - fue bautizado Henry Fielding Dickens en honor al escritor dieciochesco (Davis, 2007: 507). La admiración del autor decimonónico por su antecesor, que se hace patente en las páginas de la ficción, también dejó huella en el escenario de la vida.

\section{Progresos satíricos, tugurios de ginebra, aprendices opuestos y crueldad por etapas}

Si abordar los aspectos sórdidos de Londres constituye un punto de contacto con Tom Jones, Amelia y Jonathan Wild, este vínculo es aún más estrecho con las narrativas visuales de Hogarth. Al igual que éste (y a diferencia de Fielding), Dickens vivió su infancia en aquella metrópolis que parecía no parar de crecer. Tanto el artista dieciochesco como el novelista victoriano conocieron de cerca (y estuvieron a un tris de no poder salir de) el submundo de la pobreza y la explotación del trabajo infantil, a causa de los malos manejos financieros de sus respectivos padres. Esta experiencia se registra en la obsesión que ostentan sus respectivas producciones artísticas por retratar la facilidad con que, en el anonimato de la gran ciudad y gracias al capitalismo 
salvaje, un tropiezo puede derivar en una caída libre de donde ya no hay regreso. En palabras de la voz narrativa de Oliver Twist, "step by step, deeper and deeper down into an abyss of crime and misery, whence was no escape" (Dickens, 1993: 296). Ese mismo precipicio de delincuencia y pobreza, como se verá a continuación, es el destino de todos los sujetos satíricos de Hogarth.

Como ya se dijo, al subtitular su segunda novela The Parish Boy's Progress, Dickens establece una conexión con dos de las series satíricas más famosas de Hogarth: A Harlot's Progress (Figura 1) y A Rake's Progress (Figura 2). En sus seis y ocho escenas, respectivamente, a la manera de una historieta sin globos de texto, se narra la caída paulatina de sus protagonistas. En la primera serie de imágenes, una muchacha provinciana que llega a la gran ciudad es reclutada como prostituta, intenta comportarse como cortesana y termina al fin muriendo de sífilis en un cuartucho donde deja huérfano a un bebé que ostenta también las marcas de la enfermedad venérea. En la segunda serie, la del libertino, se presenta a un joven que abandona sus estudios en Oxford tras heredar la fortuna de su avaro padre (usurero de profesión). Con este dinero mal habido y peor valorado, el libertino emprende una carrera de despilfarro en lujos y diversiones inmorales. El declive paulatino de su dignidad, salud y condición económica lo llevan finalmente a la locura: termina recluido en Bedlam, el siniestro manicomio de Londres que, por unas monedas, podía visitarse como atractivo turístico. En un momento histórico en que estas obras de Hogarth eran tan conocidas (y vistas como representativas del talento artístico nacional) como lo es, por ejemplo, Sueño de una tarde dominical en la Alameda Central (1947), de Diego Rivera, en el México del siglo xxi, el mero título de la novela de Dickens sugería la posibilidad de un destino equivalente para el huérfano Oliver. ${ }^{17}$

El interés por representar la vida criminal "in all its wretchedness, in the squalid poverty of their lives" (Dickens, 1993: 4), es otro lazo indiscutible entre la obra de Hogarth y la de Dickens. La cita anterior pertenece al prefacio a la tercera edición de Oliver Twist, de 1841. Es así como el novelista describe su impulso por retratar en su obra el submundo delictivo, sobre el cual, a decir del escritor, había leído versiones

17 Como bien apuntan las introducciones críticas a Oliver Twist, la palabra "progress" también constituye una alusión a The Pilgrim's Progress from This World, to That Which Is to Come (1678), de John Bunyan, una biografía alegórica sobre el ascenso espiritual de un buen cristiano. De acuerdo con Jill Muller (2003), en Oliver Twist "Dickens struggles to reconcile Hogarth and Bunyan, social criticism and moral allegory" (49). Sin embargo, las implicaciones del cruce de estos hipotextos en Oliver Twist están fuera del alcance de este artículo, cuyo objetivo principal es rastrear los vínculos con la obra de Fielding y Hogarth. 


\section{Figura 1}

Arreglo de las seis imágenes de A Harlot's Progress (1732) de William Hogarth
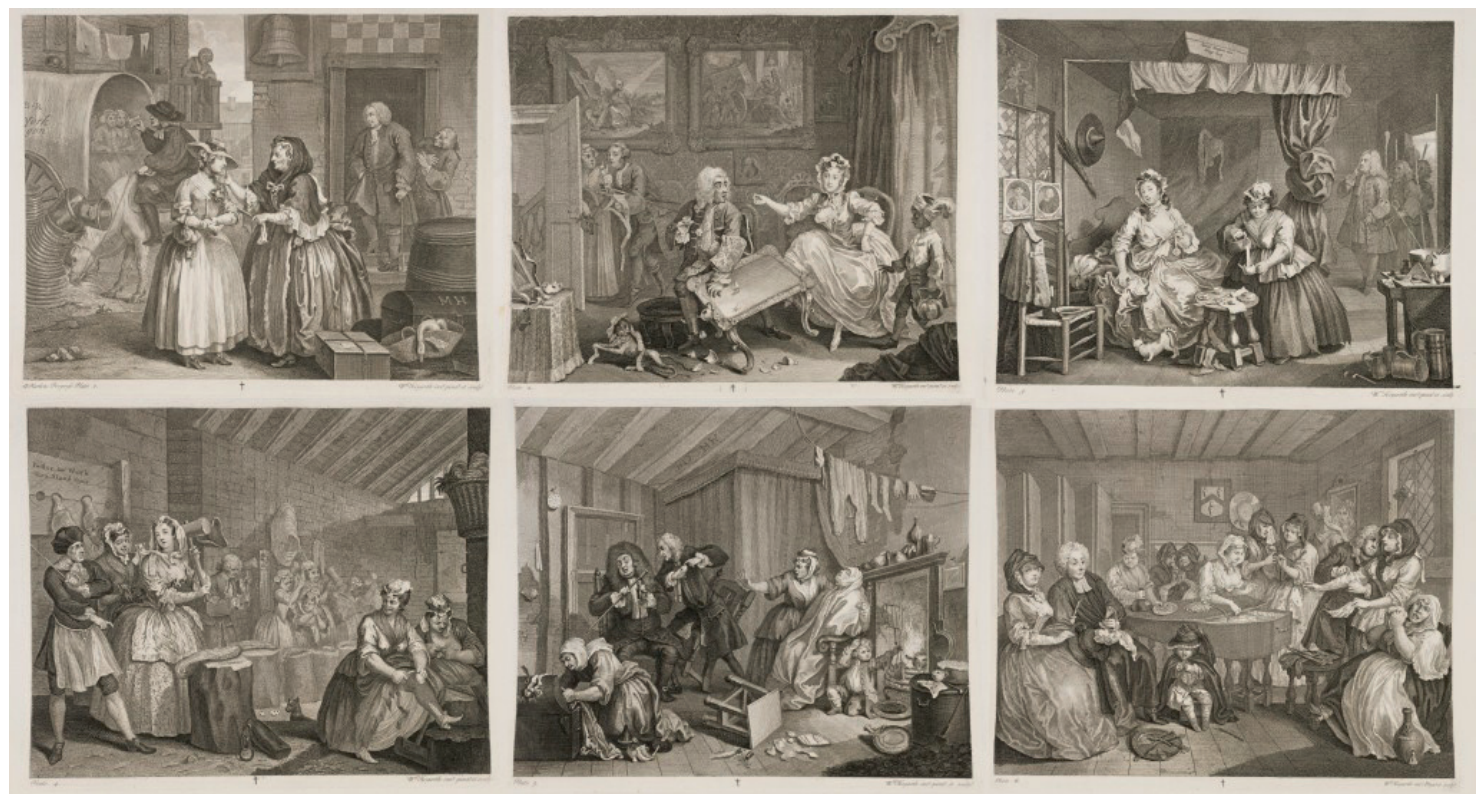

Nota: Dominio público. Fuente: https://commons.wikimedia.org/w/ index.php?curid=85994411

\section{Figura 2}

Arreglo de las ocho imágenes de A Rake’s Progress (1735) de William Hogarth

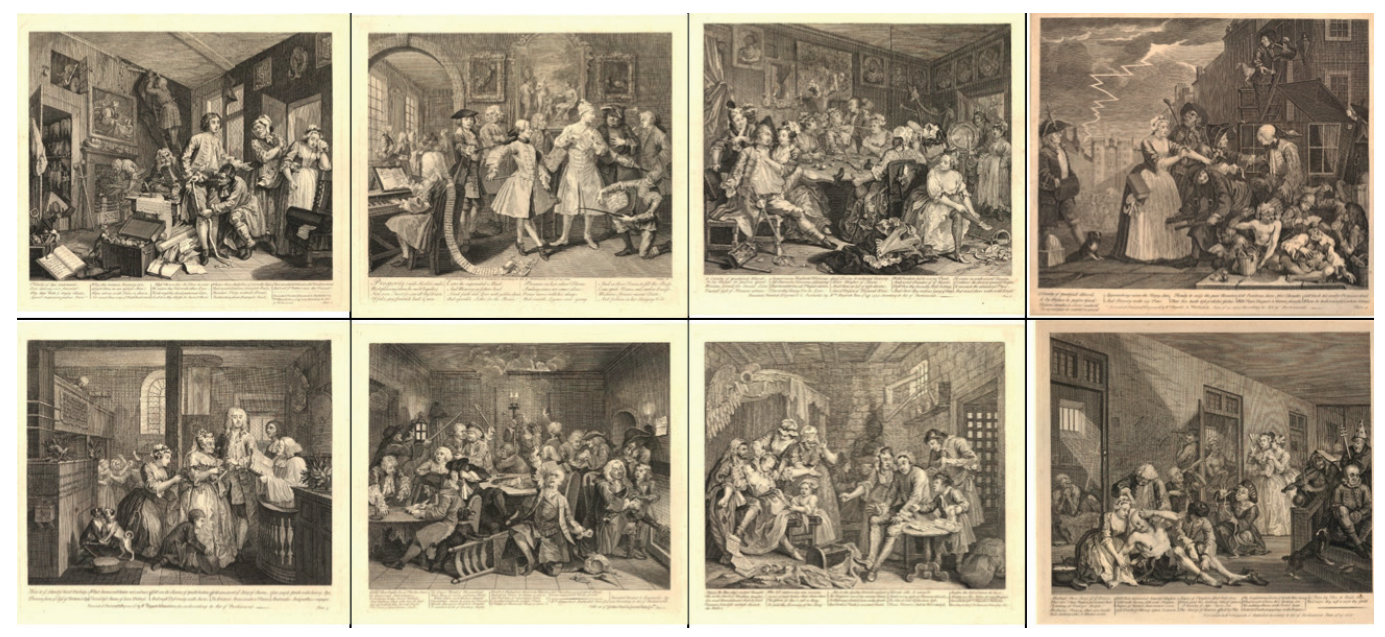

Nota: Dominio público. Fuente: https://commons.wikimedia.org/wiki/ Category:A_Rake\%27s_Progress 
romantizadas, pero "had never met (except in Hogarth) with the miserable reality" (Dickens, 1993: 4). En efecto, como apunta Murray Baumgarten (2006: 107), en su forma de representar la vida urbana en toda su sordidez, Dickens sigue una tradición que, para mediados del siglo xIx, se asociaba más con las artes visuales que con la prosa narrativa. Así pues, además de la alusión temática a los Progresos de Hogarth, la representación detallada de los ruinosos paisajes citadinos en Oliver Twist sigue de cerca la del artista plástico. Uno de los ejemplos que saltan al pensamiento es la descripción que aparece en el primer tercio de la novela sobre los barrios bajos por donde the Artful Dodger guía a Oliver de camino a la guarida de Fagin:

A dirtier or more wretched place he had never seen. The street was very narrow and muddy, and the air was impregnated with filthy odours. There were a good many small shops; but the only stock in trade appeared to be heaps of children, who, even at that time of night, were crawling in and out at the doors, or screaming from the inside. The sole places that seemed to prosper amid the general blight of the place, were the public-houses; and in them, the lowest orders of Irish were wrangling with might and main. Covered ways and yards, which here and there diverged from the main street, disclosed little knots of houses, where drunken men and women were positively wallowing in filth; and from several of the door-ways, great ill-looking fellows were cautiously emerging, bound, to all appearance, on no very well-disposed or harmless errands. (Dickens, 1993: 64-64)

Este retrato hablado sobre la desolación más absoluta posible, en la que el único atisbo de prosperidad emana de las tabernas (o "public houses"), que se presentan como causa y efecto de la pobreza y violencia que las rodea, hace eco de la iconografía distópica de Gin Lane (Figura 3), uno de los grabados más perturbadores de Hogarth. En Gin Lane se ven los mismos "drunken men and women [...] positively wallowing in filth" de los que habla Dickens, las casuchas encimadas y las figuras mal encaradas que asustan a Oliver conforme continúa siguiendo a Dodger. Asimismo, la imagen central de Gin Lane, en la que una mujer por completo perdida en el alcohol suelta de sus brazos a un bebé que cae en picada por las escaleras con destino a una muerte segura, prefigura las descripciones de los muchos infantes que mueren "from want and cold, or fell into the fire from neglect, or got half-smothered by accident" (Dickens, 1993: 20) en casas de asistencia como la que acoge a Oliver tras la muerte de su madre. 


\section{Figura 3}

Gin Lane (1751), de William Hogarth

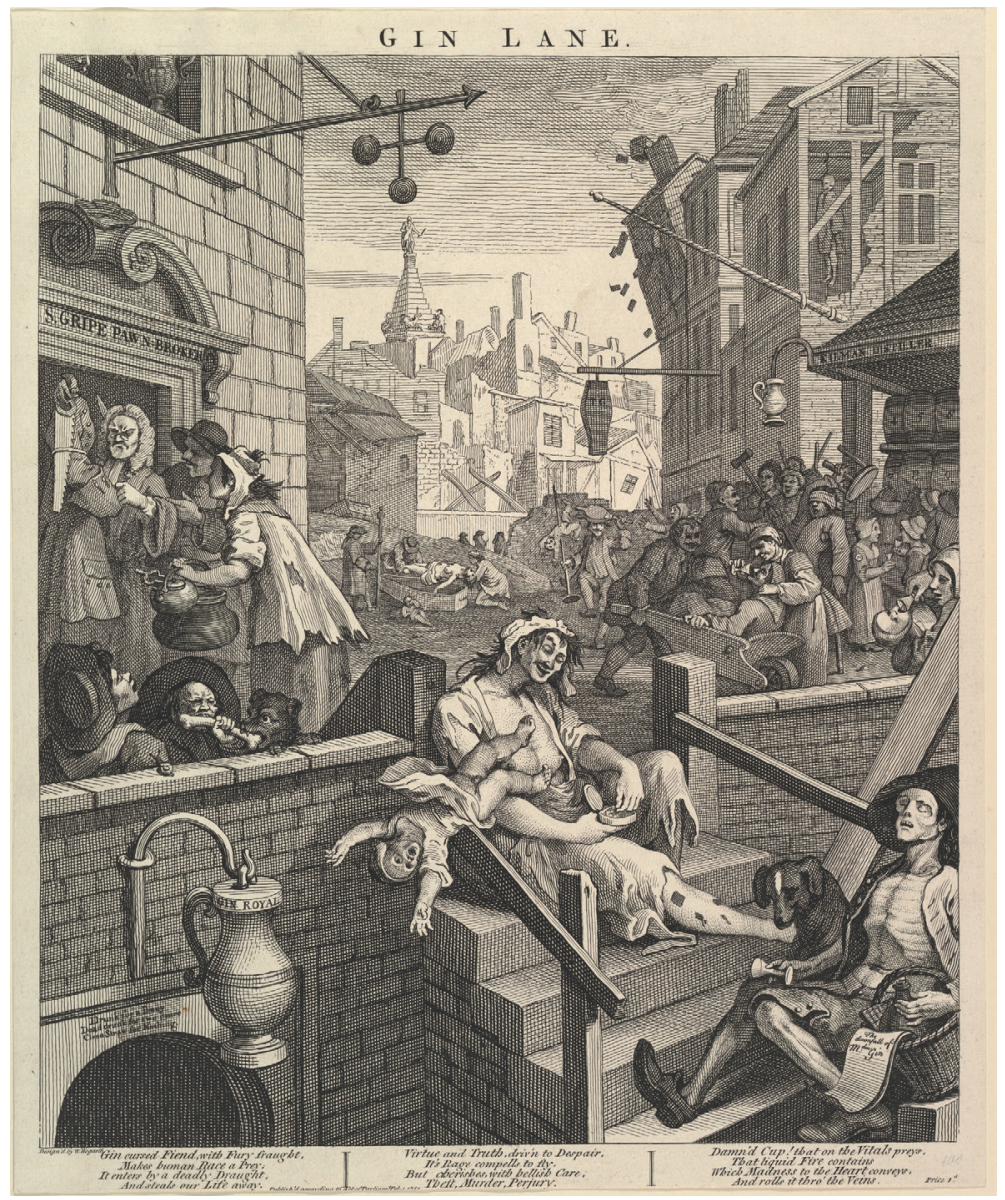

Nota: Creative Commons CC0 1.0 Universal Public Domain Dedication. Fuente: https://commons.wikimedia.org/wiki/File:Gin_Lane_MET_

DP825289.jpg

Otro eco hogarthiano digno de atender es la yuxtaposición de Oliver y Noah Claypole en cuanto polos opuestos de tipos de aprendiz, durante el episodio en la casa del enterrador. Como se recordará, a pesar de sentirse aterrado por los ataúdes en el taller de Mr. Sowerberry, Oliver desempeña bien su papel como aprendiz de éste. Noah, por el contrario, se guía por la ley del mínimo esfuerzo y vuelca sus frustraciones y resentimientos en el recién llegado. Esta caracterización dicotómica de la figura del aprendiz recuerda la de Francis Goodchild y Tom Idle, los protagonistas de Industry and Idleness (Figura 4), de Hogarth, una serie de doce grabados en la 
que se muestran las trayectorias contrarias de un aprendiz trabajador que llega a ser alcalde de Londres y uno indolente que termina siendo ejecutado por sus fechorías. Si bien Dickens no sigue de manera lineal la narrativa de Hogarth, puesto que en Industry and Idleness se muestra un recorrido completo por la vida de ambos personajes, Oliver Twist comparte con estos grabados el presentar, de manera simultánea, una oposición moralizante entre el buen y mal comportamiento y una sátira social sobre los valores inmorales de la cultura comercial. De acuerdo con Mark Hallett (2000: 221), ciertos detalles en Industry and Idleness sugieren que el camino al éxito del aprendiz industrioso se construye a costa de mantener una distancia ciega con respecto a las tribulaciones de los menos afortunados. Dickens hace algo similar cuando evita que Oliver se establezca de manera permanente en lo que parece ser un negocio redituable y socialmente respetable, pero que, como sugiere la voz narrativa con comentarios como "it was a nice sickly season; or in commercial phrase, coffins were going up" (Dickens, 1993: 50), es un giro comercial que lucra con la muerte y el dolor ajeno. Algo interesante de notar es que quien interrumpe la carrera de Oliver como aprendiz de enterrador $-\mathrm{y}$, de manera irónica, lo salva de seguir avanzando

Figura 4

Arreglo de las doce imágenes de Industry and Idleness

(1747), de William Hogarth

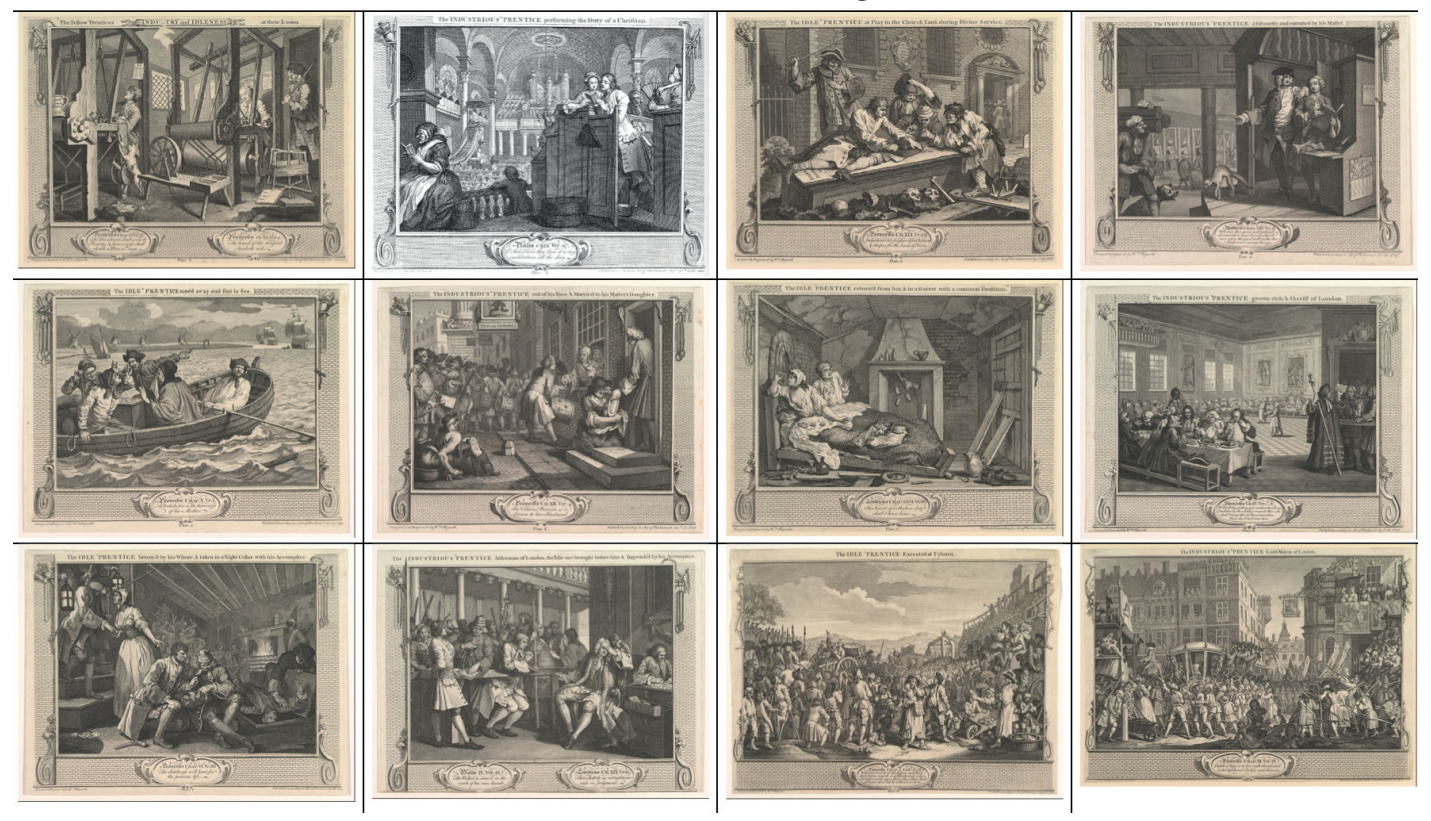

Nota: Dominio público. Fuente: https://commons.wikimedia.org/wiki/

Category:Industry_and_Idleness 
hacia un éxito económico de dudosa moralidad - es Noah, quien, al insultar la memoria de la madre del huérfano, provoca la ira de éste y le acarrea un castigo que lo orilla a abandonar la casa de Sowerberry. Éste es el único momento en toda la novela donde Oliver muestra un lado violento, o al menos de hartazgo, ante los abusos que se cometen en su contra, lo cual dota de multidimensionalidad al personaje. Así, Dickens humaniza de forma explícita el maniqueísmo con tintes irónicos de la serie de Hogarth. Al rechazar la posibilidad de que Oliver se convierta en Francis Goodchild, reafirma la crítica sutil del artista visual hacia la idea burguesa del trabajo arduo (sin importar sus fines) como ruta hacia la felicidad (equiparada con la prosperidad económica).

La caracterización del despiadado Bill Sikes encuentra un antecedente digno de atender en otra de las narrativas visuales de Hogarth: The Four Stages of Cruelty (Figura 5). En esta serie de cuatro imágenes se muestra el avance en iniquidad del sanguinario Tom Nero, quien comienza torturando a un perro con la inserción de una flecha por el ano en la primera imagen, atormenta a un caballo que ha colapsado debajo del peso insoportable de un carro de pasajeros en la segunda, asesina a su amante a sangre fría en la tercera y, tras haber sido ahorcado, termina siendo cadáver para experimentos médicos en la imagen final. Al igual que en The Four Stages, lo primero que las y los lectores de Dickens conocen sobre la violencia de Sikes es la manera en que maltrata a Bull's Eye, "a white shaggy dog, with his face scratched and torn in twenty different places" (Dickens, 1993 90), a quien patea y maldice de forma constante. Y desde luego, el tercer grabado de Four Stages, titulado "Cruelty in Perfection" (Figura 6) en donde la amante de Nero yace sin vida a sus pies, anticipa la terrible escena en que Sikes mata a Nancy. A la postre, este pasaje de la novela habría de convertirse en una de las lecturas dramatizadas más famosas de Dickens, la cual causaba horror entre los asistentes y dejaba al autor-actor exhausto (Bowen, 2000: 104). No sólo el tema del episodio en Oliver Twist es el mismo que en Four Stages; la forma en que se describe a Sikes cuando se presenta en la novela - "a stoutly-built fellow of about five-and-thirty [...] with a dirty belcher handkerchief round his neck $[\ldots]$ a broad heavy countenance $[. .$.$] and two scowling eyes; one of which displa-$ yed various parti-coloured symptoms of having been recently damaged by a blow" (Dickens, 1993: 90) - es muy similar a la figura de Nero - con todo y el pañuelo mugroso atado al cuello- que aparece en la tercera imagen de la serie de Hogarth.

Más allá de los paralelismos individuales, lo que estas comparaciones entre la obra de Hogarth y la de Dickens demuestran es el interés compartido por transmitir, 


\section{Figura 5}

Arreglo de las cuatro imágenes de The Four Stages of Cruelty (1751), de William Hogarth

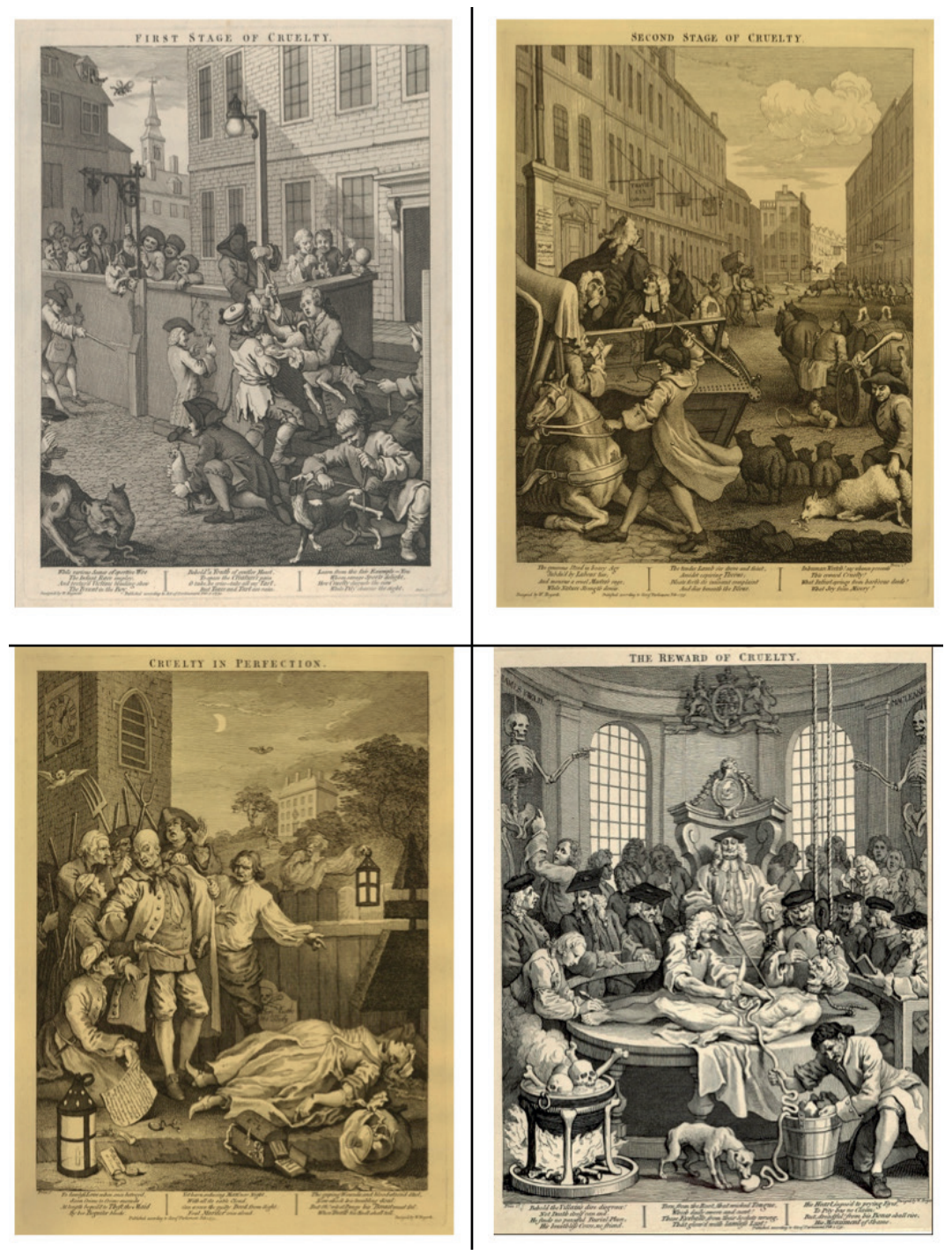

Nota: Dominio público. Fuente https://commons.wikimedia.org/wiki/ Category:The_Four_Stages_of_Cruelty

de manera vívida, sórdida y no romantizada, el caos imperante en los barrios bajos de la elegante metrópolis que los discursos nacionalistas celebraban como el centro del mundo civilizado. Lo que observa Hallett (2001) sobre cómo "Hogarth ofrecía una nueva visión polarizada de Londres como una ciudad dividida en dos mitades [...] en dos esferas culturales y sociales: una dominada por lo criminal y delictivo y la otra constituida por la virtud y el trabajo arduo" (199), puede notarse también en Dickens, 


\section{Figura 6}

Detalle de "Cruelty in Perfection", la tercera imagen de The Four Stages of Cruelty (1751), de William Hogarth

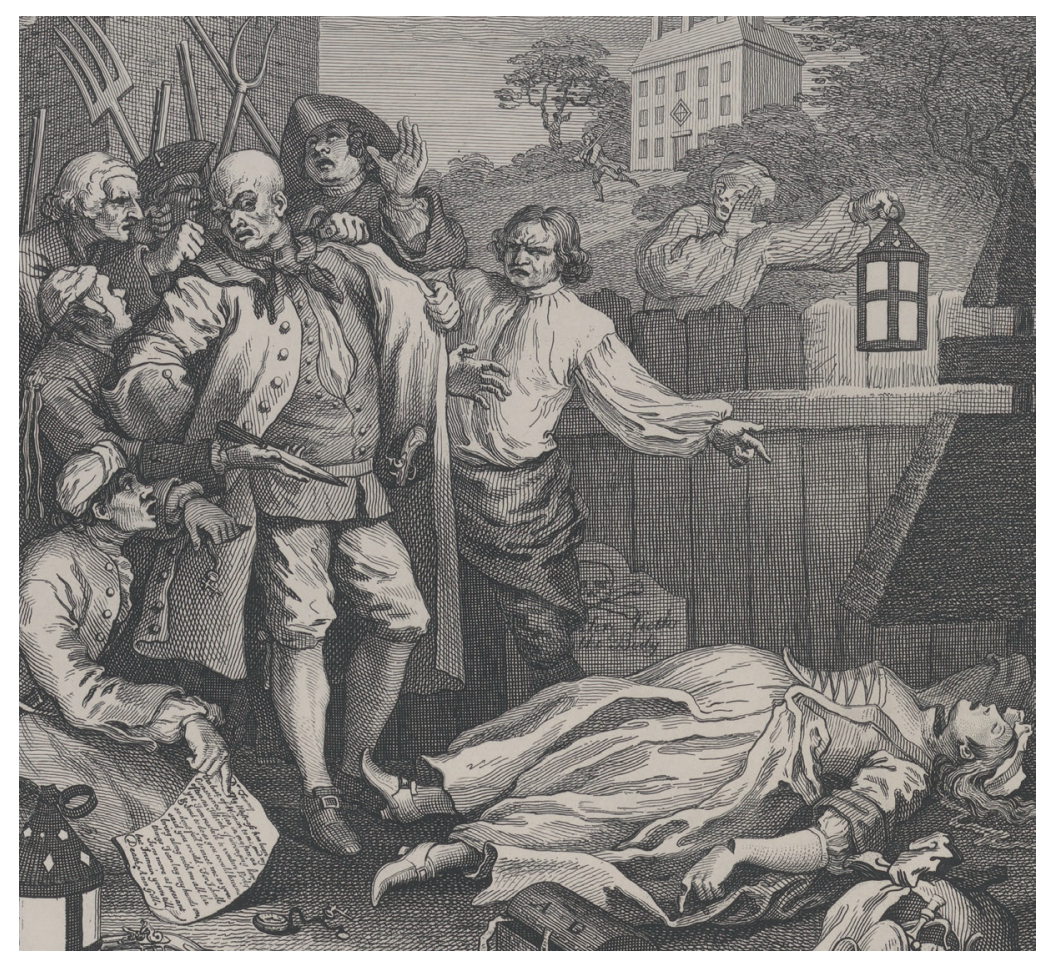

Nota: Dominio público. Fuente: https://commons.wikimedia.org/wiki/ Category:The_Four_Stages_of_Cruelty\#/media/File:Cruelty3.JPG

con la salvedad de que el escritor da un giro sentimental a personajes del bajo mundo que tienen características redimibles. ${ }^{18}$ Tal es el caso de Nancy, cuya ambivalencia entre la lealtad hacia el cruel Sikes y su sentido de justicia hacia Oliver proveen un retrato psicológico mucho más complejo de lo que sucede en las sátiras de Hogarth.

Investigaciones académicas como la que se ha presentado en estas páginas se sustentan en las indagaciones teóricas y las labores críticas que la preceden. Algo similar ocurre en la tradición literaria: las narrativas del pasado informan las del presente, las cuales, a su vez, se vuelven pasado para quienes las leen desde el futuro. Desmenuzar las capas de ese pasado y poner atención a la forma en que se transforman dentro de hipertextos casi míticos hace brillar la riqueza cultural de todas ellas.

18 "Hogarth offered a new, polarized vision of London as a city split in two halves. [...] into separate social and cultural spheres, one dominated by the criminal and the delinquent, the other made up of the virtuous and the hard-working". 
Al mismo tiempo, el rastreo de las reverberaciones de textos anteriores en obras posteriores enriquece la lectura de los hipotextos mismos, puesto que nos permite verlos bajo nuevas luces. Como se ha mostrado en estas páginas, en la segunda novela de Dickens suenan los ecos de las narrativas dieciochescas de grandes maestros de la comedia y la crítica social como lo eran Fielding y Hogarth. Notar el espíritu de las narrativas dieciochescas en Oliver Twist ilustra la manera en que Dickens trataba de dar cuenta del ritmo vertiginoso de los cambios que ocurrían a su alrededor y la devastación acarreada por el progreso, mientras observaba todo desde lo alto de la torre textual construida por sus antecesores. Tener en cuenta estos antecedentes, que eran un recuerdo mucho más reciente para quienes leían Oliver Twist en la primera mitad del siglo xix, devela ante el público lector del xxi una capa de complejidad soterrada en la novela de Dickens y demuestra, con vívidos colores, que el arte literario es una conversación constante entre tradiciones y momentos de lectura. Explorar de manera minuciosa cómo el escritor decimonónico entrelaza los tejidos de narrativas pasadas en su nuevo texto muestra las maneras en que Oliver Twist retoma y baja de tono la ironía extravagante de Tom Jones y se concentra aún más en la victimización de la inocencia de lo que hace Amelia. Además, revela las maneras en que Dickens se esfuerza por ir más allá en la campaña de desprestigio contra la figura heroica del criminal que ya emprendía Fielding en Jonathan Wild (quien, no obstante, con frecuencia hace reír — aún si es a costa suya-), al tiempo que individualiza y pone bajo la lupa a personajes del bajo mundo hogarthiano. Todo esto invita a observar con ojos nuevos la segunda novela de Dickens y también las narrativas dieciochescas aquí exploradas.

A decir de la crítica reciente, Dickens es un espécimen raro dentro del canon, puesto que su obra logra capturar tanto el interés especializado como el del público en general (Jordan, 2006: xIx). Con esto en mente, doy cierre a esta disertación académica con una alusión a la cultura popular. En "The Unquiet Dead", de la primera temporada de Dr. Who con Christopher Eccleston, un viaje del doctor al siglo XIX involucra a Dickens en la eterna lucha contra las fuerzas incognoscibles del mal. En una de las escenas finales, el escritor le pregunta al guardián del tiempo "my books, doctor, do they last", a lo que éste contesta que sí (Gatiss y Lyn, 2005: 35:35). Preocupado, Dickens insiste, "for how long". Y el doctor responde escuetamente "forever" (Gatiss y Lyn, 2005: 35:41). A casi dos centurias del debut literario de Dickens, esta hipérbole ficticia continúa siendo cierta. En consecuencia, los personajes, voces, imágenes, texturas y estructuras narrativas de Fielding y Hogarth, seguirán resonando en las páginas de Oliver Twist en años por venir. El espíritu, o, si se quiere, las sombras 
- como llama Dickens a los recuerdos en A Christmas Carol (1843) - de las narrativas pasadas residirán por siempre en la historia del huérfano literario más famoso del mundo, para quien quiera recordarlas. Humbug, podrán pensar los escépticos. Parodiando la observación final de Tiny Tim, yo digo: ¡que las diosas del arte bendigan la intertextualidad!

\section{Referencias bibliográficas}

An Essay on the New Species of Writing Founded by Mr. Fielding. (1751). W. Owen.

Baumgarten, Murray. (2006). "Fictions of the City". En John Jordan (Ed.), The Cambridge Companion to Charles Dickens. Cambridge University Press.

BELL'S LIFE IN LONDON. (1836, 12 de junio). p. 2.

Bloom, Harold (Ed.). (2008). Bloom's Classic Critical Views: Charles Dickens. Chelsea House Publishers.

Boardgame Geek. (s. f.). "Oliver Twist”. Recuperado el 12 de junio de 2021 de https:// boardgamegeek.com/boardgame/234949/oliver-twist

Bonfante, Jordan. (1970, 18 de septiembre). “The Ladies' Men of Music: The Genius behind Tom Jones and Engelbert Humperdinck". LIFE Magazine, 69(12), 48-58.

Bowen, John. (2000). Other Dickens: Pickwick to Chuzzlewit. Oxford Univesity Press.

Bowen, John; Patten, Robert L. (Eds.). (2006). Palgrave Advances in Charles Dickens Studies. Palgrave Macmillan.

Charles Dickens Museum. (s. f.) "Dickens Dream Face Mask". Recuperado el 25 de julio de 2021 de https:/dickensmuseum.com/collections/bestsellers/products/ dickenss-dream-face-mask

Coleridge, Samuel Taylor. (1835). Table Talk, 2. London J. Murray. Recuperado el 20 de julio de $2021 \mathrm{de}$ https://archive.org/details/specimensoftable02coleuoft/mode/2up

Davis, Paul. (2007). Critical Companion to Charles Dickens: A Literary Reference to His Life and Works. Facts on File.

Dickens, Charles. (1993 [1838]). Oliver Twist. Norton Critical Edition. 
Fergus, Jan. (2006). Provincial Readers in Eighteenth-Century England. Oxford University Press.

Fielding, Henry. (2005 [1749]). The History of Tom Jones, A Foundling. Penguin Classics.

Fielding, Henry. (2010 [1751]). Amelia. Broadview Press.

Garrido Ardila, Juan Antonio. (2015). “Origins and Definitions of the Picaresque”. En Juan Antonio Garrido Ardila (Ed.), The Picaresque Novel in Western Literature: From the Sixteenth Century to the Neopicaresque. Cambridge University Press.

Gatiss, Mark (Guionista); Lyn, Euros (Dir.). (2005, 9 de abril). "The Unquiet Dead" (Temporada 1, Episodio 3) [Episodio de serie televisiva]. En Russel T. Davies, Julie Gardner y Mal Young (productores ejecutivos), Dr Who. BBC One.

Hallett, Mark. (2001). Hogarth. Phaidon Press Limited.

Hutcheon, Linda. (1980). Narcissistic Narrative: The Metafictional Paradox. Wilfried Laurier University Press.

IsER, Wolfgang. (1974). The Implied Reader: Patterns of Communication in Prose Fiction from Bunyan to Beckett. Johns Hopkins University Press.

Jordan, John O. (Ed.). (2006). The Cambridge Companion to Charles Dickens. Cambridge University Press.

Keymer, Thomas. (2005). “Introduction”. En Henry Fielding, Tom Jones. Penguin Classics.

Lockwood, Thomas. (2008). "Fielding from Stage to Page". En Claude Rawson (Ed.), Henry Fielding (1707-1754): Novelist, Playwright, Journalist, Magistrate. A Double Anniversary Tribute. University of Delaware Press.

Marsh, Joss. (2006). “Dickens and Film”. En John Jordan (Ed.), The Cambridge Companion to Charles Dickens (pp. 204-233). Cambridge University Press.

McCuskey, Brian. (2001). “Dickens, Charles John Huffam (1812-1870)”. En John Powell (Ed.), Biographical Dictionary of Literary Influences: The Nineteen Century. Greenwood Press.

Michie, Allen. (1999). Richardson and Fielding: The Dynamics of a Critical Rivalry. Bucknell University Press. 
Muller, Jill. (2003). “Introduction”. En Charles Dickens, Oliver Twist (pp. 35-78). Barnes and Noble.

Newsom, Robert. (2006). "Fictions of Childhood". En John Jordan (Ed.), The Cambridge Companion to Charles Dickens (pp. 92-105). Cambridge University Press.

Patten, Robert. (2006). "From Sketches to Nickleby". En John Jordan (Ed.), The Cambridge Companion to Charles Dickens (pp. 16-33). Cambridge University Press.

Paulson, Ronald; Lockwood, Thomas. (1969). Henry Fielding: The Critical Heritage. Routledge; Kegan Paul.

Philatelic. (2012, 19 de junio). “Charles Dicken's Stamps". The British Postal Museum \& Archive Blog. Recuperado el 10 de junio de 2021 de https://postalheritage. wordpress.com/2012/06/19/charles-dickens-stamps/

Playzido. (s. f.). Oliver Twist. Recuperado el 12 de junio de https://www.playzido.com/ games/oliver-twist

Richardson, Ruth. (2012). Dickens and the Workhouse: Oliver Twist and the London Poor. Oxford University Press.

Sieber, Harry. (2018). The Picaresque. Routledge.

Zornado, Joseph L. (2001). Inventing the Child: Culture, Ideology, and the Story of Childhood. Garland Publishing.

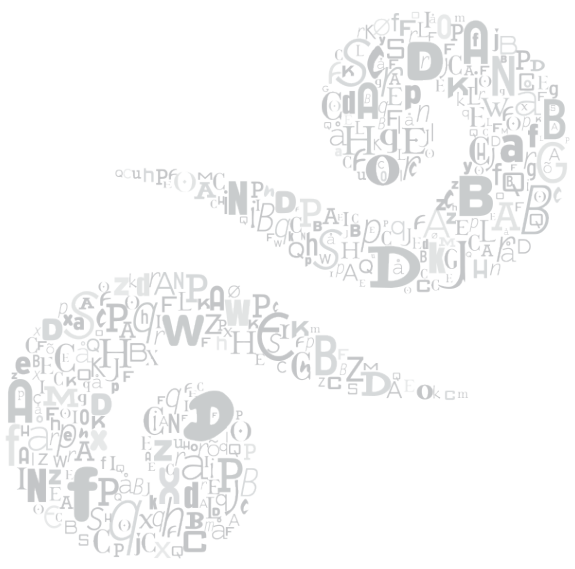

